\title{
EDUCAÇÃO PARA A MÍDIA: DA INOCULAÇÃO À PREPARAÇÃO
}

\author{
Alexandra Bujokas de Siqueira*
}

RESUMO: Este texto parte da experiência inglesa no campo da educação para a mídia e analisa as duas abordagens pedagógicas predominantes: inoculação e preparação. Para tanto, localiza tais abordagens conceitualmente nos campos da educação e da comunicação e da cultura, descreve técnicas pedagógicas e propostas de trabalho sintonizadas com a abordagem atual, a da preparação, também chamada de media literacy.

Palavras-chave: Comunicação. Educação. Estudos culturais. Media literacy. Técnicas pedagógicas.

\section{MEDIA EDUCATION: FROM INOCULATION TO PREPARATION}

ABSTRACT: Based on the British experience in the field of media education, this paper analyzes two main approaches: inoculation and preparation. It then locates such approaches in terms of concepts within the fields of education, communication and culture. It finally describes some pedagogical techniques and practical works in phase with the current approach of preparation, also called media literacy.

Key words: Communication. Education. Media literacy. Cultural studies. Pedagogical technics.

Pós-doutora em Estudos de Mídia e professora da Universidade do Sagrado Coração (Bauru, SP). E-mail: bujokas@uol.com.br 


\section{Introdução}

$\mathcal{E}$ mbora a mídia-educação ainda não seja uma área do conhecimento formalizada no currículo escolar brasileiro, com referenciais pedagógicos específicos para a área, a exemplo do que ocorre com outras áreas do currículo, na prática cotidiana da sala de aula, esse assunto é tratado, ainda que muitas vezes de forma intuitiva, por professores das áreas de Português (principalmente), História e Geografia (em menor escala).

O uso que professores e alunos faziam das mídias e o modo como os professores utilizavam os meios de comunicação na escola foram objeto de uma ampla pesquisa coordenada por Citelli (1999), primeiro focando os estudantes, entre 1992 e 1994, depois focando os professores, entre 1996 e 1998. Com o objetivo investigar como se dava a circulação dos textos "não-escolares" na sala de aula, o autor constatou que, embora professores e alunos conversassem sobre a televisão e suas polêmicas nos intervalos, esse tema praticamente não era tratado no período formal da aula, quando os docentes tendiam a se ater aos conteúdos "clássicos" dos programas oficiais, traduzidos nos livros didáticos. Tal fenômeno foi observado na época em que algumas políticas públicas voltadas à inclusão das mídias na escola estavam sendo postas em prática, tais como a TV Escola e o PROINFO. Na época, Citelli (1999, p. 216) caracterizou o momento registrado na pesquisa como "de passagem", em que a escola requisitava mudanças, mas ainda não havia encontrado mecanismos para pôr em prática as transformações necessárias.

Atentos a essas tensões entre a cultura escolar e a cultura midiática, pesquisadores brasileiros produzem referências para estudar os meios de comunicação na escola há pelo menos 20 anos (Faria, 1986, 1996, 2002; Belloni 2001; Soares 2001, entre outros). A elaboração dos parâmetros e referenciais curriculares para a educação básica (Brasil, 1998) incluiu o uso dos meios de comunicação na escola. Atualmente, o projeto "Mídias na Educação", da Secretaria de Educação a Distância, pretende estimular o desenvolvimento da área e, ainda que indiretamente, o Ministério da Cultura (MINC) e a RADIOBRÁs se comprometem com a mídia-educação, através da política de "Cultura Digital" do MINC e da proposta de trabalho da Ouvidoria da empresa jornalística do governo federal. 
Paralelamente, um exame nas principais publicações científicas das áreas de comunicação e educação mostra que esse é um assunto já tão abordado quanto os temas mais "tradicionais", tais como formação do professor, alfabetização, gestão escolar, dificuldades de aprendizagem. A pesquisa realizada por Vermelho e Abreu (2005), por exemplo, identificou 1.599 artigos sobre educação e comunicação em periódicos brasileiros, entre 1982 e 2002.

Entre nós, esses têm sido tempos de valorização da educação básica por parte do governo, que se empenha em aumentar recursos, melhorar a formação do professor, desenvolver tecnologias apropriadas, rever referenciais. É momento mais que apropriado para pensar na educação para a mídia como conteúdo curricular obrigatório.

Razões para justificar tal inclusão são relativamente fáceis de serem identificadas, principalmente pelo seu caráter de obviedade. Não se discute a centralidade dos meios de comunicação na vida pública. Além de serem grandes indústrias que geram lucro e empregos diretos e indiretos, os meios de comunicação formam o mais expressivo sistema de informação, representação, identidade e expressão, principalmente se considerarmos os avanços recentes da internet. Nesse sentido, conforme Buckingham (2000, p. 5), "tornar-se um participante ativo na vida pública necessariamente envolve o uso das mídias modernas".

Especificamente no campo da educação e seu público, há quem fale em uma nova configuração da infância, moderna e diametralmente oposta àquela tradicional, em que as crianças eram "vistas, mas não ouvidas". As crianças ganharam poder, tanto como cidadãs quanto como consumidoras, adquirindo papel de protagonistas na escolha de bens simbólicos e materiais. Conforme Buckingham (op. cit., p. 22):

Essas mudanças têm consequiências ambíguas para nossa visão da infância. Por um lado, as fronteiras entre crianças e adultos estão se borrando, enquanto, por outro, parecem estar sendo reforçadas. As crianças estão adquirindo poder e, simultaneamente, estão perdendo a capacidade de exercerem controle sobre si mesmas.

Portanto, se o campo da cultura infantil é cada vez mais produzido pela via das tecnologias de mídia - e se essas tecnologias, majoritariamente, pertencem às indústrias engajadas numa construção corporativa da infância -, então se justifica a centralidade que o estudo 
dos meios de comunicação deve ter nas escolas, os espaços privilegiados de cultivo da infância e de encaminhamento para a vida adulta, autônoma e consciente.

Entretanto, dada a complexidade do fenômeno, permanece a pergunta: como tratar a mídia pedagogicamente na escola? Diante deste quadro, o presente artigo oferece algumas referências iniciais para pensar no porquê e no como do estudo da mídia como conteúdo curricular, considerando a experiência inglesa como principal referência teórica e prática.

\section{Abordagens pedagógicas - a inoculação e a preparação}

Um exame de caráter histórico revela o interesse de educadores brasileiros pelas mídias já nos anos de 1930, quando o rádio, em seus primórdios, foi usado na educação. Formalmente, o Manifesto dos Pioneiros da Educação Nova (2006) considerou o uso dos modernos meios de comunicação da época como parte do projeto de educação pública de qualidade que eles propunham para o Brasil:

A consciência do verdadeiro papel da escola na sociedade impóe o dever de concentrar a ofensiva educacional sobre os núcleos sociais, como a família, os agrupamentos profissionais e a imprensa, para que o esforço da escola se possa realizar em convergência, numa obra solidária, com as outras instituições da comunidade. Mas, além de atrair para a obra comum as instituiçốes que são destinadas, no sistema social geral, a fortificar-se mutuamente, a escola deve utilizar, em seu proveito, com a maior amplitude possível, todos os recursos formidáveis, como a imprensa, o disco, o cinema e o rádio, com que a ciência, multiplicando-lhe a eficácia, acudiu à obra de educação e cultura e que assumem, em face das condições geográficas e da extensão territorial do país, uma importância capital.

Cerca de 80 anos depois, o que temos visto é a emergência de um campo de pesquisa interdisciplinar, que reúne educadores e comunicadores.

Um exame nos trabalhos apresentados nas últimas edições do "Congresso Brasileiro de Ciências da Comunicação", realizado pela Sociedade Brasileira de Estudos Interdisciplinares da Comunicação (INTERCOM), por exemplo, mostra que as relações entre mídia e educação têm sido exploradas, em suas diversas plataformas, em diversas regiōes do 
país: fotografia (Schultze, 2004), televisão (Argollo, 2005), rádio (Aguiar et al., 2005). Pesquisadores brasileiros estão, inclusive, recuperando os primórdios do surgimento da radiodifusão educativa no nosso país, movimento liderado por Roquete Pinto de Macedo (Moreira, 2002), um dos pioneiros da mídia no Brasil que, conforme Leal Filho (1997), tinha um perfil parecido com o de John Reith, primeiro diretor da $\mathrm{BBC}$ e internacionalmente conhecido como o defensor do papel educativo dos meios de comunicação.

Apesar da diversidade de formações originais, esses pesquisadores têm em comum a preocupação com as mútuas influências entre mídia, educação e democracia, e com seus desdobramentos, que vão das novas formas de ler e escrever, usando linguagens audiovisuais, à investigação do modo como as pessoas conhecem a realidade através da imprensa, da ficção e da publicidade.

Entretanto, qualquer que seja o recorte de estudos proposto, as pesquisas na área devem se preocupar com algumas questões paradigmáticas. Entre elas está o modo como as Ciências da Comunicação vêem a audiência - o que remete diretamente para um modelo pedagógico específico para as atividades de mídia-educação.

Um breve exame histórico dos paradigmas de estudos da audiência revela duas abordagens principais e antitéticas: público vulnerável e passivo versus crítico e ativo. E o reflexo dessas duas leituras, na educação, resultou em duas abordagens pedagógicas: uma genericamente chamada de "inoculativa" - em que um professor consciente imuniza seus alunos dos perigos da cultura midiática - e outra centrada no conceito de media literacy - em que o professor trabalha com os códigos da cultura de massa para ensinar a ler e escrever, usando tais linguagens, numa perspectiva analítica, crítica e criativa.

$\mathrm{O}$ termo media literacy vem sendo empregado na literatura acadêmica em língua inglesa desde pelo menos os anos de 1960, quando a chamada "segunda geração" dos pesquisadores da teoria da leitura (Tyner, 1998) aprofundou a compreensão dos diversos usos dessa habilidade. De lá para cá, o conceito foi ganhando forma e desdobramentos e, atualmente, com pequenas variações, pesquisadores e instituições envolvidos na área aceitam como definição de media literacy "a habilidade para acessar, compreender e criar comunicação, numa variedade de contextos" (OFCOM, 2004). 
Media literacy, portanto, se refere a um conjunto de habilidades específicas que envolvem questões de natureza técnica e informacional, e que são socialmente constituídas. Por extensão, o termo vem sendo usado para se referir à ação pedagógica necessária para promover tais habilidades. Nesse sentido, media literacy, algumas vezes, toma o lugar do termo media education. Longe de entrarem em disputa, esses dois termos tendem a se agregar, para constituir um campo interdisciplinar e expandido do conhecimento, que reúne contribuições de diversas ciências, tais como a psicologia, a sociologia, a lingüística e a semiótica. Tradicionalmente, os campos da comunicação e da educação têm se empenhado em investigar problemas relativos ao uso das mídias em contextos educativos.

Buckingham (2000) fornece um panorama histórico, dividido em quatro etapas: os longínquos anos de 1930 (e as tentativas pioneiras de inocular as pessoas contra os efeitos nocivos da mídia), os anos de 1960, com a popularização dos chamados estudos culturais britânicos (que propõem na escola a reflexão sobre o modo como as pessoas convivem com as mídias, no período que ficou conhecido como o da abordagem da "desmistificação"), os anos de 1980 (quando o estudo das mídias passou a ser incluído formalmente na educação formal) e a época atual, que ainda trabalha a partir da perspectiva dos estudos culturais, adaptados às inovações tecnológicas.

Agora, educadores não se preocupam mais em inocular seus alunos, mas sim em prepará-los para usar, de modo consciente e proveitoso, os benefícios que as novas plataformas podem oferecer. De antemão, um alerta deve ser feito: a preparação para usufruir os benefícios se justifica quando esses benefícios existem, concretamente. No campo da educação, é preciso haver o acesso às tecnologias, escolas com infra-estrutura adequada e professores preparados. No campo da comunicação, uma política democrática que fomente a produção diversificada, responsável e comunitária, calcada na perspectiva do serviço público de radiodifusão.

Entretanto, na Inglaterra, assim como no Brasil, ainda é mais fácil encontrar a abordagem inoculativa, que tem lá suas razóes para persistir. Para entender o porquê desta perspectiva ter sido predominante no passado, e muito valorizada ainda hoje, é preciso contextualizar a educação para a mídia num quadro maior, o dos estudos em comunicação. 
De fato, a metalinguagem no campo da comunicação costuma identificar o período pós-Primeira Guerra Mundial como um marco inicial significativo das pesquisas em mídia, porque foi naquele período que o termo "propaganda" se popularizou e trouxe consigo a idéia de vulnerabilidade da audiência. Conforme Brooker e Jermyn (2003, p. 7): "Na Europa e nos Estados Unidos houve uma onda de interesse em tentar entender como a propaganda funcionava e de medo de que uma elite restrita de manipuladores hábeis pudesse usar esse conhecimento para controlar a mente e o comportamento das pessoas".

Ao final da guerra, a Europa viu crescerem sistemas ditatoriais no leste, que, entre outros recursos, usaram figuras carismáticas amplamente divulgadas para obter a adesão popular. Os pesquisadores viram surgir um uso muito potente das então modernas tecnologias de mídia e cunharam os termos "sociedade de massa" e "cultura de massa".

Foi neste contexto histórico e cultural que floresceram as já tão comentadas investigações da escola empírica da Universidade de Colúmbia, lideradas por Robert Merton e Paul Lazarsfeld. No contexto das primeiras investigações empiristas, a intenção era saber se a propaganda tinha mesmo tanto efeito e, neste caso, de que modo essa influência ocorria e como proteger as pessoas. Pegando carona nessas discussōes, educadores americanos e europeus se engajaram na produção de materiais pedagógicos e atividades para a sala de aula que pudessem "inocular" os estudantes dos efeitos perigosos da propaganda e da cultura massificada.

$\mathrm{Na}$ Inglaterra, a abordagem da inoculação já era encontrada em textos sobre filosofia da educação, escritos no final do século XIX e início do século XX. Conforme Halloran (1986, p. 57):

A abordagem inoculativa ou moral surgiu de uma profunda preocupação dos educadores e dos críticos literários que queriam proteger as crianças da poderosa influência e dos efeitos nocivos das mídias de massa. Crianças e jovens eram considerados uma audiência suscetível e maleável, facilmente exploráveis pelos novos produtos de mídia.

Um dos textos mais famosos daquele período foi escrito por Frank Raymond Leavis, escritor e crítico literário, junto com seu aluno Denys Thompson. Publicado em 1933, o livro se chamava Culture and environment e alertava para os efeitos alienantes que mídias da época estavam provocando, propondo atividades pedagógicas que mostrassem 
Educação para a mídia: da inoculação à preparação

aos alunos os perigos da imprensa popular e do cinema. Conforme Leavis e Thompson (1933, p. 102):

A distração é melhor exemplificada pela imprensa popular - isso se "dissipação" não for a melhor palavra (...). Nos jornais populares, a tendência dos ambientes modernos é desencorajar tudo que não seja de interesse imediato e raso, as mais superficiais, automáticas e baratas respostas mentais e emocionais são exibidas de modo mais desastroso.

O raciocínio básico era o de que, com a supremacia da produção mecanizada de bens materiais e simbólicos, a cultura veiculada pela imprensa popular e pelo cinema padronizava respostas emocionais "baratas", inculcando a preferência por prazeres imediatos, obtidos sem nenhum esforço intelectual. Nesse sentido, o que justifica a opção pela alta cultura na escola é a necessidade do esforço intelectual, que leva ao aprendizado. Na medida em que a cultura fora da escola estimula uma abordagem oposta, cabe aos professores encontrarem formas de proteger seus alunos da influência corrupta da cultura massificada (Leavis, 1933).

Entretanto, eles não eram extremistas. Os autores admitem que certos filmes poderiam ser considerados obras de arte e usados como critério para evidenciar produtos ruins. Agindo dessa forma, o professor daria às crianças os parâmetros para discriminar os diversos produtos disponíveis.

Nas entrelinhas dos argumentos desses autores é possível identificar outra tendência paradigmática da pesquisa em comunicação: a teoria crítica e o conceito de indústria cultural (Adorno \& Horkheimer, 1985). Convém recobrar os pontos fundamentais deste paradigma, a fim de enriquecer a análise das propostas pedagógicas inglesas.

Os produtos culturais produzidos pelas mídias modernas, dizia Adorno, agem como engrenagem de um sistema maior, o da produção capitalista, calcada na produção em larga escala e na apropriação da maisvalia, feita pelo capital sobre o trabalho, e mantendo o controle de uma situação economicamente desfavorável para a maioria. Emerge daí a necessidade de um apoio simbólico ao projeto de expropriação de riquezas e controle dos comportamentos sociais.

Nesse sentido, literatura, música e filme são produzidos com dois objetivos principais: gerar lucro financeiro e satisfazer as necessidades de lazer da massa de trabalhadores. Para fomentar o lucro, é preciso 
estimular a venda em larga escala. A saída encontrada pela indústria cultural é criar necessidades imediatamente satisfeitas pelo romance ou pela balada musical. Ocorre que a satisfação deve ser apenas momentânea, a fim de que surja uma nova necessidade a ser satisfeita por outro produto. Nesse contexto, cada produto deve ser consumido de modo ligeiro e superficial, para que não se gaste muito tempo e esforço com ele. Prescindir do esforço, explica Adorno, vem muito a calhar quando o produto é dirigido àqueles que o consomem nas horas do "falso lazer" - o intervalo entre os períodos de trabalho, em que a pessoa deve espairecer apenas o suficiente para se colocar em condiçôes de trabalhar no dia seguinte. Fecha-se, assim, um ciclo: trabalhadores que usam seu dinheiro para consumir produtos culturais feitos pelos donos do capital; produtos estes que satisfazem as necessidades de lazer dos trabalhadores, para continuarem trabalhando, sem a necessidade do esforço da reflexão.

Adorno e Horkheimer foram criticados, tachados de elitistas e acusados de fazer generalizaçōes sem ter dados empíricos suficientes. Contudo, a força do pensamento dos dois se comprova com o uso renovado que muitos pesquisadores, no Brasil e no exterior, têm feito de seus conceitos fundamentais.

Embora tenham se tornado a referência imediata deste paradigma, Adorno e Horkheimer não estavam sozinhos. O fenômeno que eles identificaram nos Estados Unidos dos anos de 1940 e 1950 foi encontrado de modo similar também na Inglaterra.

$\mathrm{Na}$ medida em que o tempo passava, mais jovens aderiam aos produtos da mídia e, concomitantemente, rejeitavam a crítica feita pela escola, despertando preocupação entre educadores e intelectuais. Um texto emblemático deste período é The uses of literacy, publicado por Richard Hoggart (1957), um pesquisador que cresceu num bairro operário e voltou às suas origens para tentar entender o modo como a classe trabalhadora se apropriava dos tais produtos culturais padronizados e baratos.

Antes de comentar o livro de Hoggart, é preciso fazer uma breve recuperação do contexto social em que o estudo foi produzido. $\mathrm{O}$ autor viveu o período pós-Segunda Guerra, quando os países industrializados da Europa viveram o chamado pacto social - o acordo entre capitalistas e trabalhadores que evitou as revoluçóes sangrentas e fez surgir 
a chamada social-democracia, calcada no modo de produção capitalista, equilibrada por um Estado provedor das chances mínimas de vida, tais como moradia, alimentação, saúde e educação. É claro que essas conquistas não vieram facilmente, mas foram fruto de uma atuação desgastante e apaixonada de líderes trabalhadores que lutaram pela legalização dos sindicatos, pela aprovação das leis trabalhistas e pela oferta de serviços sociais. Foi um grupo minoritário que aprendeu a ler em projetos de caridade e depois lutou pela institucionalização da escola para os seus filhos. Quando esses direitos elementares começaram a se sedimentar, pessoas como Hoggart viram surgir uma nova geração, que desdenhava a escola e gastava seu - pouco - dinheiro com revistas "picantes” e máquinas que tocavam músicas americanas nos pubs ingleses.

O autor se propôs, então, a examinar essa nova (e paradoxal) realidade de perto. No capítulo "A nova arte das massas: sexo em pacotes brilhantes", ele descreve o uso que jovens trabalhadores fazem das revistas masculinas e da música "encaixotada" nas máquinas acionadas por moedas:

Eu tenho em mente aqueles bares que estão se disseminando em cidades com pouco mais de 1.500 habitantes e que estão se tornado o ponto de lazer e encontro de rapazes e moças. Os homens entre 15 e 20 anos são a maioria, com seus ternos desalinhados e gravatas estampadas e um jeito americano relaxado. A maioria deles não pode pagar uma rodada de milk-shakes e tomam xícaras de chá por uma ou duas horas enquanto gastam suas moedas - e essa é a maior razão para estarem ali - ouvindo as músicas gravadas nas máquinas. Em geral, são uma dúzia de músicas que são trocadas de tempos em tempos, praticamente todas são americanas e cantadas, e o estilo do canto é bem diferente daquele normalmente ouvido na BBC. Algumas melodias são cativantes, algumas são adaptadas para aquele tipo de apresentação, então elas têm aquele tipo de batida que é atualmente popular, muitas usam efeitos de eco. Elas são apresentadas com grande competência, e o tocador permite um som alto o suficiente para um teatro, apesar de estar numa lanchonete no meio da rua. Um jovem balança um ombro ou olha fixo, tão atrevido quanto Humphrey Bogart, através das cadeiras tubulares. Comparado com o pub da esquina, este é um modo estreito e pálido de evasão (...). Muitos dos clientes - suas roupas, seus estilos de cabelo, suas expressôes faciais -, tudo indica que eles vivem em um imenso mundo mítico, composto por poucos elementos que eles tiram daquela vida americana (...). Eles não têm objetivos, ambições, proteções e nem crenças. (1957, p. 249) 
O tom de lamento é muito evidente nesta passagem do texto e talvez esta seja uma das razóes que levaram os entusiastas da cultura de massa a criticarem o saudosismo de intelectuais como Adorno, Leavis e Hoggart. Entretanto, antes de aderir à crítica contemporânea, talvez seja prudente refletir sobre as razões do lamento, em função do contexto histórico e cultural em que ele foi feito.

Tanto na Europa como nos Estados Unidos da segunda metade do século Xx, houve quem lutasse bravamente pelos direitos sociais, entre eles o direito à escola pública, gratuita e de qualidade, que ensinasse às crianças da classe trabalhadora os mesmos conhecimentos que, até então, estiveram disponíveis apenas para a elite. Que conhecimentos eram esses? Eram as idéias iluministas que sacudiram os dois séculos anteriores, transformaram regimes políticos, revigoraram as sociedades, trouxeram liberdade e autonomia ao pensamento humano, criaram as bases da tecnologia e das ciências modernas.

Quando, enfim, todo esse cabedal simbólico estava em vias de ser popularizado, eis que surgem máquinas que transportam palavras, sons e imagens, mas que se concentram em outros conteúdos, tais como a aventura sexual, a fantasia e o romance, problemas pessoais "resolvidos no tapa" etc., empregando procedimentos estéticos que prendem a atenção, mas não vão muito além disso. Para quem um dia sentiu a própria mente brilhar ao provar da ciência, da arte e da filosofia, a duras penas, é de se lamentar que as novas gerações jogassem essas oportunidades fora. $\mathrm{Na}$ tentativa de reverter esse quadro é que esses autores propuseram a inoculação, através do estudo crítico das mídias.

Ocorre que a situação era mais complexa e ia além do lamento. Buckingham (2000, p. 12) avalia como um dos problemas da abordagem inoculativa o fato de seus idealizadores a considerarem certa e garantida: "A educação para a mídia era considerada, automaticamente, capaz de direcionar a criança para uma apreciação da alta cultura, para comportamentos moralmente saudáveis, para crenças mais racionais e politizadas". Todo educador com experiência razoável sabe que a realidade não é essa.

De fato, nos contextos socioeconômicos em que os modelos de exploração comercial da mídia são hegemônicos, é mais comum encontrar uma abordagem de resistência escolar a esses aparatos, como é o caso do Brasil. Ocorre que uma condução mais democrática, pluralista 
e enriquecedora dos serviços de comunicação midiática passa também pelo modo como as novas geraçôes aprendem a enxergar o rádio, o cinema, a imprensa, a televisão e a internet. Nesse ponto, surge a responsabilidade da escola. E a experiência internacional tem mostrado que o foco na "literacia" em mídia tem trazido mais resultados do que a crítica protecionista. Vejamos esse percurso.

\section{A promoção da media literacy}

Até mesmo Hoggart, aparentemente tão crítico da massificação americanizada da cultura jovem dos anos de 1950 e 1960, concluiu que, no fundo, a educação tinha a ganhar com essas mídias porque o repertório da classe trabalhadora era, de algum modo, melhorado com a presença da cultura de massa. Havia um trabalho criativo ali. A cultura tradicional dos operários migrantes não estava sendo aniquilada pela industrialização, mas eles estavam forjando outro tipo de repertório, que mesclava o tradicional e o contemporâneo e cujos elementos, depois de depurados, expressavam um senso distintivo daquele grupo como trabalhadores de determinados setores e como moradores de locais específicos. Hoggart (1957, p. 149-150) descreve um exemplo dessa apropriação, a partir da música:

A música popular laica é mais amplamente representativa do gosto da classe trabalhadora do que as bandas e os corais religiosos e fornecerá o principal exemplo aqui. Eu não falo do jazz e suas variantes que surgiram nos últimos 30 anos. Eu penso naqueles livros que vêm com discos encartados e são vendidos em papelarias (The Magazine of Song Hits, The Hit Parade). Eles contêm as letras, mas não as partituras de cerca de uma centena de músicas, novas e antigas, todas misturadas.

Se os produtores de tais livros e discos misturavam o tradicional e o novo, é porque sabiam que era assim que seus consumidores aprovavam. Portanto, é uma evidência de que a assimilação não era tão passiva assim: havia uma complexa mistura de novidade e tradição nos produtos culturais feitos para a classe operária.

Hoggart também descreve as seções de cantoria promovidas nos clubes, aos sábados à noite. O período de 1880 a 1910 foi a época áurea desses clubes (embora eles existam até hoje e tenham sido muito 
populares nos anos de 1950 e 1960), que viviam de contribuições dos operários e vendiam cerveja mais barata do que os pubs, tinham mesas para jogar dardo, bilhar, cartas ou dominó e, nos finais de semana, um pianista para acompanhar quem se aventurasse a cantar para os presentes. $\mathrm{O}$ autor descreve o modo como esses cantores de ocasião se apresentavam: escolhiam velhas canções populares, mas entonavam a voz feito cantores de orquestra - gravados nos livros-discos -, embora mantivessem seus sotaques peculiares.

A partir daí, concluía-se que o impacto das mídias era mais complexo do que se supunha, de que havia uma interação ao invés de uma simples reação e que, na escola, os educadores deveriam perguntar "o que é que seus alunos faziam com os materiais midiáticos e não o que é que esses materiais faziam com os alunos" (Murdock, 1973, p. 71).

Assim, ao se voltar para os hábitos e ações cotidianas dos jovens que estavam aderindo à cultura de massa da época, Hoggart iniciou um modo de abordar a mídia na escola que depois foi aprimorado e sistematizado por Stuart Hall e Paddy Whannel, no livro The popular arts, publicado em 1964. Neste período, a ênfase na hegemonia da cultura de massa começou a ser substituída pelo reconhecimento de que havia diferenças entre produtos de certa categoria (cinema e música popular, por exemplo) e que havia níveis de qualidade diferentes em um mesmo produto (uma música com melodia não muito criativa, mas com letra expressiva e original). A partir daí, a escola incrementou as habilidades necessárias para o uso das mídias, incluindo as formas de acesso aos diversos produtos, além da avaliação.

Assim, no médio prazo, a intencionalidade aditiva, enriquecedora e encorajadora se fez presente com mais ênfase do que aquela crítica, inibidora e subtrativa, em relação às novas formas de cultura. Esse caminho se tornou mais nítido com o livro de Hall e Whannel.

The popular arts foi escrito a partir da experiência dos autores como professores de inglês nas modernas escolas secundárias da Inglaterra dos anos de 1950. É um livro dividido em quatro partes: a primeira define os termos "cultura popular", "artes populares" e "cultura de massa”. A segunda parte descreve os temas significativos que emergem das culturas populares, tais como a violência e o romance, a terceira parte discute as implicações sociais desses temas e a quarta parte propõe modos de abordar tais temas na sala de aula. Alguns trechos do 
Educação para a mídia: da inoculação à preparação

livro merecem ser comentados, a fim de compreender de que modo se deu a transição da inoculação para a "literacia".

Embora tenham mais de 50 anos e se refiram ao que hoje chamamos de "velhas mídias" (o cinema, a TV e o disco), muitos dos insights de Hall e Whannel continuam atuais. Um deles se refere às razôes pelas quais os educadores tendem a manter atitude defensiva quando são convidados a usar os meios de comunicação em suas aulas (perpetuando a abordagem inoculativa): a escola é geralmente um ponto de interação de muitos conflitos sociais e culturais; o professor deve valorizar a cultura para justificar inclusive a sua própria existência, é pressionado a gerar, ao mesmo tempo, cidadãos críticos e produtores capacitados e sabe que, para muitos dos seus alunos, o que ele ensina é pouco, frente às necessidades emocionais que os jovens têm. Por fim, o professor é visto como o guardião de uma cultura que, na verdade, não lhe pertence totalmente - é provável, aliás, que o repertório da maioria dos educadores seja bem mais próximo ao do aluno do que daquele tradicionalmente preconizado para a escola.

Tratar da mídia é, portanto, enfrentar questôes de caráter cultural, tendo em mente o tipo de sociedade na qual os meios têm influência e as respostas que as pessoas dão a cada produto midiático, tais como filmes, música e romances "água com açúcar". Assim, a gênese da abordagem pedagógica da "preparação para usar as mídias" está na capacidade de fazer distinções. E, conforme Hall, só podemos fazer distinçôes quando estudamos cada produto, em detalhe.

Os autores dão um belo exemplo quando se detêm sobre o cinema (popular) de Charlie Chaplin. O argumento é de que esses filmes são a configuração contemporânea da mesma matriz cultural popular da Idade Média, que resistiu às revoluções iluministas e se manteve até a invenção do cinema. Para evidenciar tal idéia, os autores recuperam a estrutura de uma forma de arte popular muito antiga e comum na Inglaterra, as chamadas ballads broadsides. Eram canções de autoria anônima, que tratavam de aspectos relacionados diretamente com o mundo concreto, transmitidas com pequenas variações de geração a geração e apresentadas por artistas do povo, num contato direto com o público. Esse modo de arte sobreviveu à chegada da imprensa, conviveu com a ascensão do romance popular e evoluiu para outra forma de arte, os chamados music halls. Estes eram apresentações teatrais feitas na rua, que 
misturavam música e dramatização. A principal mudança entre o broadside e o music hall é que, neste último, os artistas deixaram de ser anônimos e passaram a desenvolver um estilo típico, que era capaz de cativar e controlar a audiência. Assim, no music hall, a interação entre o artista e o público não se dava mais pelo uso de um repertório comum acerca da realidade concreta, mas sim pelo reconhecimento de certas estruturas estéticas e convenções na representação, que criavam um ar de familiaridade. As pessoas procuravam um determinado artista por causa do seu estilo de apresentar. Conforme Hall e Whannel (1964, p. 60),

O music hall foi uma forma transitória peculiar do fim da era vitoriana e apareceu num daqueles estranhos momentos em que, sob condiçóes muito especiais, a comunidade se entrega a uma arte comum por um breve período que é, justamente, o começo de uma mudança principal.

A mudança, neste caso, se refere ao momento de transição da arte popular tradicional (os broadsides) para as artes de massa: cinema, teatro de comédia e dramatização na TV. Nessa passagem, diminui a interatividade entre o artista e o público e isso é compensado com o aumento do uso da sensação. Entretanto, há um elemento de continuidade: a relação do artista com a audiência. O cinema de Charlie Chaplin é um exemplo paradigmático (1964, p. 65):

Chaplin trouxe à tona o personagem vagabundo nos quadros humorísticos. Quando ele deixou o estúdio de Keystone, ele diminuiu o ritmo da atuação até que um modo mais íntimo e sutil de atuar apareceu - a ironia e a melancolia tiveram espaço para se desenvolver. Desde "O vagabundo" até "Tempos modernos", vimos o aprofundamento dessa figura, a emergência de um estilo cômico transcendente, que uniu o ritmo e a ingenuidade de Keystone com a lentidão e a tristeza da mímica. O personagem adquiriu profundidade e ar sombrio. Os pequenos gestos de extravagância ou de bravura de aparência, a confiança seguida do desapontamento, a comemoração de uma pequena vitória destacam e ajustam as habilidades e as emoções daquele primeiro período. $\mathrm{O}$ estilo transformou as gags individuais em um tipo criativo: o do pequeno homem contra o mundo. Esse era o seu estilo pessoal na performance (especialmente em Luzes da cidade e A corrida do ouro) que recriou o vínculo entre Chaplin e sua audiência. Neste ponto, ele deixou de ser simplesmente um inventivo ator de comédia cinematográfica e se tornou um artista popular.

Segundo os autores, em termos estruturais, o que diferencia a estética da arte popular e da arte erudita é que esta nos guia para experimentar 
Educação para a mídia: da inoculação à preparação

sentimentos desconhecidos ou que não sabíamos que tínhamos, enquanto aquela não conta nada de novo; apenas nos ajuda a conhecer sentimentos que temos com mais intensidade, ou a notar suas sutilezas. Assim, o charme e o carisma do artista são ingredientes fundamentais, o estilo pessoal é a via para atingir a audiência, mas o artista o faz com respeito. "É expressivo do gosto popular, mas não o explora" (Hall \& Whannel, 1964, p. 72).

$\mathrm{O}$ quadro a seguir sistematiza algumas das características que diferenciam a arte popular midiatizada da cultura massificada pelos meios de comunicação.

\section{Quadro 1}

Características da arte popular e da arte massificada

\begin{tabular}{|l|l|}
\hline \multicolumn{1}{|c|}{ Características do popular } & \multicolumn{1}{c|}{ Características do massificado } \\
\hline $\begin{array}{l}\checkmark \text { Representa uma continuidade da arte } \\
\text { anônima produzida em contato com o público. }\end{array}$ & $\begin{array}{l}\checkmark \text { Destrói os traços de individualidade e as } \\
\text { idiossincrasias do artista. }\end{array}$ \\
$\begin{array}{l}\checkmark \text { Permite ao artista exercitar um estilo pessoal } \\
\text { reconhecível pelo público. }\end{array}$ & $\begin{array}{l}\checkmark \text { Vende a pessoa do artista, mas não seu estilo } \\
\text { pessoal. }\end{array}$ \\
$\begin{array}{l}\checkmark \text { O estilo é desenvolvido no "duelo" com a } \\
\text { audiência, através da criação artística. }\end{array}$ & $\begin{array}{l}\checkmark \text { O suposto estilo não passa de uma série de } \\
\text { truques para projetar uma imagem reconhecível. }\end{array}$ \\
$\begin{array}{l}\checkmark \text { Uma vez que o elo com a audiência é } \\
\text { estabelecido, o artista se perde no meio da } \\
\text { sua obra. }\end{array}$ & $\begin{array}{l}\checkmark \text { O narrador não se perde na narrativa. } \\
\text { O homem por trás da produção é vendido }\end{array}$ \\
$\begin{array}{l}\checkmark \text { Usa a estilização e a convenção para } \\
\text { selecionar, enfatizar e reforçar aspectos, a fim } \\
\text { de encantar a audiência com alguma surpresa } \\
\text { criativa. }\end{array}$ & $\begin{array}{l}\checkmark \text { Ao invés de estilização e convenções, usa } \\
\text { estereótipos e fórmulas para simplificar a } \\
\text { experiência, mobilizar um estoque-padrão de } \\
\text { sentimentos que mantêm a audiência conectada. }\end{array}$ \\
\hline
\end{tabular}

Em resumo, os autores sugeriram que, explorando detalhadamente a diversidade de produtos culturais midiáticos disponíveis, o educador poderia selecionar aqueles que expressam a legitimidade da arte popular e tratá-los pedagogicamente na escola.

Para além das produções de caráter artístico, os autores também pensaram nos produtos focados, por exemplo, na não-ficção e na 
informação jornalística. Também aqui é preciso distinguir as produções que criam uma comunicação popular daquelas que se contentam em tentar ludibriar o público. Assim, essa esfera da produção não é necessariamente arte, mas o sentido popular pode ser identificado num documentário ou num debate televisivo que ponha em destaque um valor caro ao público. "Trata-se de um tipo de qualidade que não é necessariamente calculado, mas que acontece nesses programas através de passagens, ligações de idéias, conclusões" (Hall \& Whannel, 1964, p. 91).

The popular arts forneceu uma reflexão legítima, franca e abrangente e se tornou um marco da abordagem da preparação para usar as mídias na escola.

Cerca de 40 anos depois, nos países em que a mídia-educação já foi integrada ao currículo, há uma infinidade de projetos, eventos e materiais pedagógicos próprios. Apesar da diversidade de temas e conteúdos, as abordagens contemporâneas têm em comum o foco na preparação para usar as mídias, materializadas em seis técnicas pedagógicas principais (Buckingham, 2000): análise textual, estudo do contexto, análise de conteúdo, estudo de caso, tradução, simulação e produção. Todas essas estratégias têm em comum dois princípios básicos de aprendizagem: o de que o aluno já tem conhecimentos importantes sobre mídia (em geral mais amplos que os do professor), mas que muitos dos aspectos realmente significativos na área são desconhecidos. E são esses os aspectos que devem ser ensinados, usando-se uma ou mais técnicas, que são resumidas e exemplificadas no quadro 2.

$\mathrm{Na}$ Inglaterra, especificamente, uma organização se destaca no desenvolvimento de cursos e materiais pedagógicos para a mídia-educação: o British Film Institute. Uma breve descrição de um exemplo de atividade realizada por este instituto ajuda a compreender os modos como a abordagem da "literacia" se concretiza em casos concretos.

\section{Estudo de um caso}

Considere-se o curso "TV Advertising", ${ }^{1}$ oferecido pelo British Film Institute para alunos entre 11 e 16 anos, realizado no National Film Theatre, South Bank, Londres. Com duração de quatro horas, o programa foi dividido em três partes: exposição teórica de conceitos e análises, atividades práticas e conversa com um profissional da área. 


\section{Quadro 2}

\section{Técnicas pedagógicas, objetivos e exemplos}

\begin{tabular}{|c|c|c|}
\hline TÉCNICA & OBJETIVO & EXEMPLO \\
\hline Análise textual & $\begin{array}{l}\text { Fazer do familiar estranho, a fim de } \\
\text { encorajar a formação de um ponto de } \\
\text { vista a partir da constatação de } \\
\text { evidências. Fornecer profundidade ao } \\
\text { invés de abrangência. }\end{array}$ & $\begin{array}{l}\text { Estudo do trailer de um filme de } \\
\text { sucesso: descrição detalhada do script, } \\
\text { identificação dos recursos usados para } \\
\text { ligar as seqüências, das conotaçōes e } \\
\text { associaçóes, das intertextualidades. }\end{array}$ \\
\hline Análise contextual & $\begin{array}{l}\text { Estudar padrôes de linguagem e } \\
\text { valores em exemplos de uma mesma } \\
\text { categoria. Complementa a análise } \\
\text { textual, fornecendo mais abrangência. }\end{array}$ & $\begin{array}{l}\text { Estudo das seqüências de abertura } \\
\text { de telejornais: características da } \\
\text { audiência imaginadas pelos } \\
\text { produtores, recursos técnicos e } \\
\text { estéticos empregados, recursos para } \\
\text { criar apelo e manter a audiência. }\end{array}$ \\
\hline Estudo de caso & $\begin{array}{l}\text { Conhecer todas as etapas do processo } \\
\text { de produção: definição do público- } \\
\text { alvo, construção da mensagem, } \\
\text { marketing e publicidade, respostas da } \\
\text { audiência, controvérsias decorrentes } \\
\text { do modo como os produtos culturais } \\
\text { são feitos }\end{array}$ & $\begin{array}{l}\text { Estudo do lançamento de um } \\
\text { videogame violento: quem são os } \\
\text { potenciais compradores, quais são } \\
\text { suas expectativas em relação ao jogo, } \\
\text { onde o jogo é anunciado, como são } \\
\text { compostos os anúncios, quais são os } \\
\text { argumentos das pessoas que criticam } \\
\text { jogos desse tipo. }\end{array}$ \\
\hline Tradução & $\begin{array}{l}\text { Conhecer melhor as relações entre } \\
\text { linguagem e representação, as } \\
\text { mudanças que ocorrem quando um } \\
\text { conteúdo é tratado em mídias } \\
\text { diferentes e em gêneros diferentes, } \\
\text { para audiências diferentes. }\end{array}$ & $\begin{array}{l}\text { Estudo das representações da guerra: } \\
\text { como o jornal impresso descreve } \\
\text { batalhas e como são as fotos } \\
\text { publicadas; como o jornal televisivo } \\
\text { descreve e quais imagens veicula; } \\
\text { como a literatura descreve uma } \\
\text { batalha, como a pintura clássica o faz, } \\
\text { como o filme produzido em } \\
\text { Hollywood o faz. }\end{array}$ \\
\hline Simulação & $\begin{array}{l}\text { Promover experimentos úteis para } \\
\text { tratar questôes controversas que } \\
\text { emergem das rotinas de produção, } \\
\text { e que são temas centrais da mídia- } \\
\text { educação, tais como a violência, o } \\
\text { poder, a identidade etc. }\end{array}$ & $\begin{array}{l}\text { Estudo da caracterização de } \\
\text { personagens em programas de ficção } \\
\text { (novelas e filmes): traços físicos, } \\
\text { comportamentais, valores, atitudes na } \\
\text { trama. Escolher um personagem em } \\
\text { particular e construir o personagem } \\
\text { oposto. Introduzir o oposto na trama } \\
\text { e simular os acontecimentos } \\
\text { decorrentes. }\end{array}$ \\
\hline Produção & $\begin{array}{l}\text { Criar situaçōes-problema } \\
\text { paradigmáticas da cultura midiática, } \\
\text { para serem resolvidas pelos } \\
\text { estudantes, em trabalhos de equipe. } \\
\text { Deve englobar as propostas de todas } \\
\text { as outras técnicas, para não virar uma } \\
\text { mera celebração das vontades do } \\
\text { aluno. }\end{array}$ & $\begin{array}{l}\text { Criar um programa de rádio ou de } \\
\text { TV, de caráter educativo, que não } \\
\text { exista na grade de programação das } \\
\text { emissoras: público-alvo, horário de } \\
\text { exibição, duração, gênero, plot, } \\
\text { vinheta de abertura e de } \\
\text { encerramento, orçamento, captação } \\
\text { de recursos, atribuição de tarefas, } \\
\text { critérios de avaliação. }\end{array}$ \\
\hline
\end{tabular}


Na primeira parte, a educadora Eileen Lewis mostrou filmes publicitários de creme dental feitos nos anos de 1960, 1980 e 2000. A ingenuidade dos primeiros comerciais, o avanço tecnológico e o apelo sexual nos mais recentes animaram o tratamento de aspectos históricos, da regulamentação, além da identificação dos gêneros e formatos na publicidade: narrativas, infomerciais, testemunhais, comédia, endossamento por uma celebridade.

A questão da regulamentação foi tratada a partir de um episódio recente no Reino Unido: a proibição feita pela Advertising Standards Authority dos anúncios da marca de sucos Tango, conhecida por seus comerciais de caráter surrealista, em que um personagem de comédia faz coisas absurdas para tomar um suco. Em um desses comerciais, ele veste uma roupa antiga de mergulhador, feita de metal, enche o capacete com laranjas e vai a um ferro velho, onde um operador de guindaste magnético o ergue e solta, repetidas vezes. Com a queda, as laranjas viram suco dentro do capacete. Depois de receber reclamaçóes dos pais - argumentando que a marca Tango incentivava as crianças a fazerem coisas absurdas e perigosas -, a autoridade governamental que regula a propaganda decidiu proibi-la.

No curso do British Film Institute, a retomada desse episódio foi tratada em uma atividade de sondagem. Os estudantes receberam um questionário com 12 afirmações do tipo "a publicidade se sustenta muito em estereótipos”, "nós somos persuadidos, contra nossa vontade, a comprar produtos que não precisamos", "eu adoro assistir a filmes publicitários porque eles são divertidos e criativos", "é bom que pessoas menores de 16 anos sejam protegidas de assistir a propaganda de junk food", "não é interesse dos publicitários sustentar valores e pontos de vista tradicionais", "os programas só existem para oferecer a audiência aos publicitários" etc. Em cada uma dessas afirmações, os alunos deveriam marcar se concordavam fortemente, concordavam, não tinham certeza, discordavam ou discordavam fortemente. Os resultados seriam tabulados pelos professores de cada grupo, para sustentar um debate posterior, em sala de aula.

A seguir, Jez Stewart, curador de não-ficção do British Film Institute, apresentou um estudo de caso da evolução da propaganda da Coca-cola no Reino Unido. Foram exibidos oito filmes, que ilus- 
Educação para a mídia: da inoculação à preparação

tram a evolução nos argumentos da marca. Stewart começou com uma declaração de um chefe de operações da Coca-cola:

Nós nos comunicamos com nossos consumidores com muito cuidado. De fato, em 107 anos, os comerciais da Coca-cola têm feito somente uma promessa fundamental: que uma Coca gelada é deliciosa e refrescante... nada mais, nada menos.

$\mathrm{O}$ palestrante questionou se isso era mesmo verdade e passou a exibir os filmes. Em 1956, ia ao ar o primeiro comercial da Coca-cola, no canal Independent Television (ITV). Com duração de 15 segundos, mostrava um casal dançando ao som de uma orquestra. Quando a música acabava, eles se dirigiam à mesa e tomavam uma Coca-cola. Em 1963, um comercial mais sofisticado (com recursos de edição inexistentes no primeiro filme) mostrava um nadador, um tenista e um jogador de boliche que, após suas performances esportivas, tomavam o refrigerante. Em 1972, a marca inovou a trazer um coral formado por jovens de diversas etnias, vestindo jeans rasgados e roupas em estilo hippie, cantando a seguinte música:

Eu queria comprar para o mundo um lar / e mobiliar com amor / plantar árvores de maçã e criar abelhas de mel / e esparramar pombas brancas./ Eu queria ensinar o mundo a cantar / em perfeita harmonia / eu queria comprar para o mundo uma Coca / e mantê-la como companhia / porque essa é a coisa real./ O que o mundo precisa hoje / é de uma Coca / que é a coisa real.

A música virou um hit da época e marcou a transição do modo de fazer comercial da Coca-cola, que passou a associar a marca com valores e comportamentos sintonizados com o público-alvo do produto. Depois disso, vieram os filmes com pessoas reais, os slogans, as estratégias de campanha, até culminar no "Always Coca-cola", praticado até hoje. Stewart finalizou sua apresentação mostrando como diversos valores foram sendo associados à marca, dependendo das características do público-alvo que os donos da Coca-cola pretendiam atingir com cada campanha.

Após o almoço, vieram dois publicitários profissionais. Jonathan Tapper, da agência Ogilvy and Mather, mostrou como são feitas as campanhas da Honda, em função do posicionamento da marca previamente definido, com ênfase na produção do comercial "A possible dream", recentemente lançado no Reino Unido. Nesse comercial, um homem 
de meia-idade e bigode à moda vitoriana sai de casa de manhã e, na medida em que o tempo vai passando, ele dirige diversos modelos da Honda, dos mais antigos ao mais recente. As cenas imitam filmes famosos como os da série James Bond, Missão Impossivel e Rambo. A música fala em chegar à estrela mais distante, trilhar o caminho nunca percorrido, enfrentar o infinito etc. Após a exibição do filme, Tapper exibiu uma versão feita por estudantes, em que o logotipo da Honda foi trocado pela bandeira da Inglaterra, e mostrou em que medida a publicidade trabalha com valores tão abstratos, que podem ser aplicados a situações tão diferentes.

Depois, veio a parte prática. Os alunos se dividiram em grupos e receberam uma ficha de atividades, com instruçôes para planejar a campanha de um refresco. Deveriam definir público-alvo, slogan, criar um script de comercial, detalhando cenas e recursos técnicos usados. As propostas apresentadas, em geral, foram da simples imitação dos padrôes convencionais da publicidade às imitações burlescas, com alguma pretensão crítica. $\mathrm{O}$ evento foi encerrado com um conversa informal entre os alunos e o publicitário Jake Wynne, conhecido por rejeitar campanhas para a rede McDonald's e por ter como cliente o The Guardian, jornal britânico de esquerda. Wynne falou sobre ética na publicidade, descreveu o perfil do profissional, enfatizando a necessidade de ter interesse na área de Media Studies desde a escola secundária (na Inglaterra, a mídia é estudada na disciplina optativa Media Studies e na disciplina Cidadania)

Em linhas gerais, o curso "TV Advertising" se enquadra na abordagem da preparação para usar a mídia, enfatizando questões de caráter técnico, político e ideológico. Certamente, a capacidade de reunir exemplos significativos de modo pedagógico é o ingrediente que garante o sucesso de uma proposta como essa.

\section{Considerações finais}

A proposta deste artigo foi discorrer sobre as duas principais abordagens pedagógicas para estudo da mídia na educação (a inoculação e a preparação), a fim de contribuir para os "como e porquês" da inclusão deste assunto no currículo escolar brasileiro. Como pôde ser visto nas páginas anteriores, trata-se de uma rica abordagem que engloba tecnologia, linguagem e cultura, e que vem ao encontro das 
necessidades da educação escolar contemporânea, preocupada em preparar o jovem para viver autonomamente na atual configuração da sociedade. Longe de praticar uma abordagem instrumental, simplesmente calcada no ler e escrever, usando mídias, a proposta da preparação para usar as mídias se fundamenta no desenvolvimento de capacidades de metalinguagem, localização de informaçōes, análise de evidências, avaliação e leitura crítica das mensagens, vistas dentro de um contexto social, institucional e econômico da comunicação de massa, contexto que afeta pessoas e práticas. Vista desse modo, a mídia-educação requer dos estudantes habilidades de pesquisadores - que normalmente não são ensinadas no currículo tradicional -, tais como selecionar material, organizar evidências, interpretar dados, chegar a conclusóes. Promovendo esta abordagem pedagógica, certamente a escola irá oferecer contribuição decisiva para fomentar um debate mais informado sobre o papel e o funcionamento dos meios de comunicação. No longo prazo, tal debate deve melhorar a nossa democracia.

Recebido em setembro de 2007 e aprovado em novembro de 2007.

\section{Nota}

1. Curso assistido pela autora em $1^{\circ}$ de dezembro de 2006, no British Film Institute, em Londres (Inglaterra).

Referências

ADORNO, T.W.; HORKHEIMER, M. Dialética do esclarecimento. Rio de Janeiro: Zahar, 1985.

AGUIAR, C.B. et al. O rádio e a universidade em sintonia com a mídia-educação. In: CONGRESSO BRASILEIRO DE CIÊNCIAS DA COMUNICAÇÃO, 28., 2005, Rio de Janeiro. Anais... Rio de Janeiro: INTERCOM, 2005.

ARGOLLO, R.V.A.S. De Big Brother a Pokémon: a TV como recurso pedagógico. In: CONGRESSO BRASILEIRO DE CIÊNCIAS DA COMUNICAÇÃO, 28., 2005, Rio de Janeiro. Anais... Rio de Janeiro: INTERCOM, 2005.

BELlONI, M.L. O que é mídia-educação. Campinas: Autores Associados, 2001. 
BRASIL. Ministério da Educação. Secretaria de Educação Fundamental. Parâmetros curriculares nacionais: terceiro e quarto ciclos do ensino fundamental: língua portuguesa. Brasília, DF: MEC/SEF, 1998.

BROOKER, W.; JERMYN, D. The audience studies reader. New York: Routledge, 2003.

BUCKINGHAM, D. Media education: literacy, learning and contemporary culture. Cambridge, MA: Polity, 2000.

CITELLI, A. Comunicação e educação: a linguagem em movimento. São Paulo: SENAC, 1999.

FARIA, M.A. O jornal na sala de aula. São Paulo: Contexto, 1986.

FARIA, M.A. Como usar o jornal na sala de aula. 9. ed. São Paulo: Contexto, 1996.

FARIA, M.A.; ZANCHETTA, J. Para ler e fazer o jornal na sala de aula. São Paulo: Contexto, 2002.

HALL, S.; WHANNEL, P. The popular arts. Londres: Hutchinson Educational, 1964.

HALLORAN, J.D.; JONES, M. Learning about media: communications and society. Paris: UNESCO, 1986. (paper).

HOGGART, R. The uses of literacy. Middlesex: Penguin; Chatto \& Windus, 1957.

LEAL FILHO, L. A melhor TV do mundo: o modelo britânico de televisão. São Paulo: Summus, 1997.

LEAVIS, F.R.; THOMPSON, D. Culture and environment: the training of critical awareness. London: Chatto \& Windus, 1933.

MOREIRA, S.V. Roquette Pinto, empreendedor de mídia educativa. In: CONGRESSO BRASILEIRO DE CIÊNCIAS DA COMUNICAÇÃO, 25., 2002, Salvador. Anais... Salvador: InTERCom, 2002.

MURDOCK, G.; PHELPS, G. Mass media and the secondary school. London: MacMillam, 1973.

OFCOM. OFCOM's strategy and priorities for the promotion of media literacy: a statement. London: Office of Communications, 2004. 
SOARES, I.O. Comunicação e criatividade na escola. São Paulo: Paulinas, 1998.

SOARES, I.O. Caminhos da Educomunicação. São Paulo: Salesiana, 2001.

SCHULTZE, A.M. Fotografia e educação: a escola como formadora de leitores críticos da imagem midiática. In: CONGRESSO BRASILEIRO DE CIÊNCIAS DA COMUNICAÇÃO, 27., 2004, Porto Alegre. Anais... Porto Alegre: InTERCOM, 2004.

VERMELHO, S.C.; AREU, G.I.P. Estado da arte da área de educação e comunicação em periódicos brasileiros. Educação \& Sociedade, Campinas, v. 26, n. 93, p. 1413-1434, 2005.

TEIXEIRA, A. Manifesto dos Pioneiros da Educação Nova. Disponível em: <http://www.pedagogiaemfoco.pro.br/heb07a.htm>. Acesso em: 12 dez. 2006.

TYNER, K. Literacy in a digital world. Mahwa: Lawrence Erlbaum, 1998. 